\title{
Medicalização do parto: os sentidos atribuídos pela literatura de assistência ao parto no Brasil
}

\author{
Medicalization of childbirth: the meanings attributed by the \\ literature on childbirth care in Brazil
}

Lucia Regina de Azevedo Nicida (https://orcid.org/0000-0002-6517-463X) ${ }^{1}$

Luiz Antônio da Silva Teixeira (http://orcid.org/0000-0001-8871-0928) ${ }^{1}$

Andreza Pereira Rodrigues (http://orcid.org/0000-0002-1873-5828) ${ }^{2}$

Claudia Bonan (http://orcid.org/0000-0001-8695-6828) ${ }^{1}$
${ }^{1}$ Instituto Fernandes Figueira, Fundação Oswaldo Cruz. Av. Rui Barbosa 716, Flamengo. 22250-020 Rio de Janeiro RJ Brasil. lucia.nicida@gmail.com

${ }^{2}$ Escola de Enfermagem Anna Nery, Universidade Federal do Rio de Janeiro. Rio de Janeiro RJ Brasil.

\begin{abstract}
This study analyzes the meanings attributed to the concept of the medicalization of childbirth from a narrative review of the literature in national journals published between 2000 and 2017. It is based on the more general concept of medicalization - understood as the process by which medicine broadens and consolidates its area of activity in the various sectors of society and the different formulations of the concept conceived by twentieth-century scholars. Five categories were created that related the medicalization of childbirth with interventions, professional dispute, violation of the rights of pregnant women, the birth scenario, and the impact of the medicalization of society. In the first four categories there is a predominance of meanings that explore the interface between medicalization and humanization, considered two analytical super categories, with a predominance of a critique of the medicalized model. Setting aside this analysis model, the medicalization of childbirth category as a reflection of the medicalization of society focuses on a sense of medicalization of childbirth as part of a broader process involving different actors who are part of the care process, pointing to a possibility of more in-depth analysis in which it considers the complex connection between modern health and society.
\end{abstract}

Key words Medicalization, Childbirth care, Women's health
Resumo Este estudo analisa os sentidos atribuídos ao conceito de medicalização do parto a partir de uma revisão narrativa de literatura em periódicos nacionais publicados entre 2000 e 2017. Parte-se da concepção mais geral sobre medicalização - entendida como o processo pelo qual a medicina amplia e consolida a sua área de atuação nos diversos campos da sociedade - e das diferentes formulações do conceito concebidas por estudiosos do século XX. Foram construídas cinco categorias que relacionaram medicalização do parto com: intervenções, disputa profissional, violação de direitos das gestantes, cenário do parto e reflexo da medicalização da sociedade. Nas quatro primeiras categorias encontramos um predomínio de sentidos que exploram uma interface entre medicalização e humanização, constituindo-se como duas supercategorias analíticas, com um predomínio de uma crítica ao modelo medicalizado. Fugindo a este modelo de análise, a categoria medicalização do parto como reflexo da medicalização da sociedade se concentra em torno de um sentido de medicalização do parto como parte de um processo mais amplo que envolve diferentes atores que seriam copartícipes no processo de assistência, apontando para uma possibilidade de análise mais aprofundada em que considera a complexa conexão entre saúde e sociedade moderna.

Palavras-chave Medicalização, Assistência ao parto, Saúde da mulher 


\section{Introdução}

No Brasil, o parto realizado em hospitais e acompanhado por equipe médica se afirmou a partir das três últimas décadas do século $\mathrm{XX}^{1}$. Tal modelo contribuiu significativamente para a redução da mortalidade materna e perinatal ${ }^{2,3}$, no entanto, trouxe consigo críticas e incertezas, na maior parte das vezes relacionadas ao processo de estandardização de procedimentos caracterizados como intervenções no processo fisiológico do parto. Ainda nos anos 1950 surgiram as primeiras críticas ao modelo medicalizado ${ }^{4}$, mas seria na década de 1980 que as reivindicações por mudanças na assistência ao parto, se intensificariam, em um movimento que no Brasil foi denominado de "humanização do parto".

As propostas dos grupos pela "humanização do parto" foram debatidas em uma conferência internacional de consenso sobre o uso apropriado de tecnologia no pré-natal, no parto e no nascimento ${ }^{4,5}$, organizada pela Organização Pan-Americana de Saúde (OPAS/OMS), em Fortaleza, em 1985. A conferência reconheceu o parto como um evento natural e normal, afirmando que não havia justificativas para taxas de cesárea acima de 10 a $15 \%{ }^{6}$. Além do incentivo ao parto vaginal, a OMS recomendou mudanças nas rotinas marcadas por intervenções técnicas e tecnológicas, alertando que quando utilizadas de forma desnecessária e excessiva elas poderiam causar danos tanto para a mãe quanto para o bebê $\hat{e}^{3,4}$.

As recomendações da OMS tiveram um grande impacto no Brasil e serviram de referência para a elaboração das políticas sobre o parto, para as campanhas do Ministério da Saúde e para os movimentos sociais pela humanização, que se tornaram cada vez mais atuantes. Em maio do ano 2000, como fruto desse movimento, o Ministério da Saúde, criou o Programa de Humanização no Pré-natal e Nascimento (PHPN) ${ }^{4,7}$. Esse processo fazia parte de um movimento amplo que contou com o ativismo feminista, e afirmava a necessidade de ampliar o poder de decisão das mulheres em relação às questões de saúde, em especial a relacionada ao parto, incorporando na sua pauta de discussão questões referentes aos direitos reprodutivos e sexuais, relacionando-as aos direitos humanos ${ }^{4,8,9}$.

As reflexões e movimentos em busca da mudança do modelo de assistência ao parto potencializaram o surgimento de publicações de artigos que exploram os modelos assistenciais, o panorama e o cenário do parto no Brasil, muitas vezes, trazendo como instrumental teórico o conceito de medicalização, utilizado para descrever os diferentes processos relacionados ao binômio: medicina-parto ${ }^{3}$.

A observação desses artigos mostra que a utilização do conceito de medicalização assume diferentes significados, a partir de diferentes visões sobre a relação entre a utilização de procedimentos e tecnologias médicas no nascimento e condições mais seguras, afetuosas e confortáveis de parir. Partindo do argumento da existência dessa multiplicidade de visões, este estudo tem como objetivo discutir como os artigos publicados em periódicos nacionais entre os anos 2000 e 2017 tematizaram o parto e analisar quais sentidos tem sido atribuído ao conceito de medicalização do parto.

\section{Perspectivas de análise em torno do conceito de medicalização}

O conceito de medicalização tem sido trabalhado por teóricos e estudiosos das relações entre medicina e sociedade desde a década de 1950. Entre os primeiros estudos sobre o tema, encontramos aqueles que caracterizaram medicalização como o processo em que comportamentos relacionados à vida e a problemas sociais passaram a ser tratados pela medicina, mais especificamente pela psiquiatria. Referências importantes entre estes estudos são os trabalhos de Barbara Wootton e Thomas Szasz, realizados nas décadas de 1950 e $1960^{10,11}$.

$\mathrm{Na}$ década de 1970, Irving Zola ${ }^{12}$ caracterizou a medicalização como o processo pelo qual a medicina passa a desempenhar um papel de controle social, posição que até então era desempenhada pela religião e pela lei. Neste processo, o médico, a partir de uma suposta neutralidade e objetividade, e investido de um poder moral, assume uma posição que lhe permite indicar o tratamento do corpo e da mente. Para o autor, além de tratar da doença, a medicina acaba por ir mais além, identificando, controlando e produzindo novos hábitos ${ }^{12}$.

Ainda na década de 1970, Michel Foucault ${ }^{13}$ discute o processo iniciado no final do século XVII em que, a partir do nascimento da Medicina Moderna e da Higiene, surge uma nova configuração de saberes e poderes, na qual o indivíduo e a sociedade passaram a sofrer, cada vez mais, a intervenção da medicina. Sem fazer uso específico do termo medicalização, em seus primeiros trabalhos, Foucault analisou não só o exercício do poder médico sobre o indivíduo, mas a complexa rede de poder como aspecto fundamental para o 
funcionamento da sociedade moderna. No seu entender, a ampliação da jurisdição médica sobre a sociedade não se caracteriza como um simples reflexo do avanço tecnológico da medicina, mas como um aspecto constitutivo da sociedade ${ }^{13,14}$.

Qualificando a medicalização como uma forma de expropriação do cidadão em relação aos saberes e práticas sobre seu corpo e sua saúde, Ivan Illich ${ }^{15}$ afirma que a medicalização da vida se tornou uma ameaça na medida em que retirou do paciente a capacidade de gerir sua própria saúde; e em meio a ações de prevenção, diagnósticos e terapias retiram a sua autonomia pessoal. Atuando como uma empresa, a medicina tomou para si o monopólio do conhecimento científico, impedindo que esse conhecimento pudesse ser partilhado com os próprios consumidores de seus serviços ${ }^{15}$. Illich afirmava que o maior dano que essa empresa médica estaria causando seria a iatrogênese, que se constituiria como uma nova epidemia de doenças provocadas pela própria medicina ${ }^{15,16}$.

No final da década de 1990, Débora Lupton ${ }^{17}$ desenvolve a crítica à ideia da medicalização como controle social. Na sua perspectiva, o poder médico não existe por si, e os pacientes não devem ser vistos como vítimas de uma engrenagem maquiavélica. A autora vê a medicalização como um encontro entre consumidores e profissionais, onde o poder do médico se constitui e se mantém no âmbito de um desejo/intenção do pacien$\mathrm{te}^{17}$. Nesse sentido, Lupton afirma que o poder e o conhecimento médico ao invés de serem vistos como elementos de repressão, deveriam ser analisados como elementos de sedução nas sociedades modernas, e que associados a existência de uma cumplicidade entre os sujeitos envolvidos tornaria possível a sua própria manutenção ${ }^{17}$.

Numa perspectiva diversa, Peter Conrad ${ }^{18}$ vê a medicalização como um processo heterogêneo, marcado por interesses múltiplos e de caráter irregular, existindo vários graus de medicalização em diferentes sociedades e momentos históricos. Esta heterogeneidade estaria relacionada a inúmeros aspectos, tais como: o interesse e apoio dos médicos em relação ao que está sendo alvo da medicalização; a existência de comportamentos e sintomas mais medicalizáveis do que outros e sensíveis a competição entre diferentes grupos de especialistas; etc. Além disso, diferenças de gênero, de categorias profissionais, de grupos sociais, de faixas etárias, tornariam os indivíduos mais ou menos susceptíveis de serem medicalizados ${ }^{18}$.

Mais recentemente Clarke et al. ${ }^{19}$ chamaram atenção para a transformação do conceito de medicalização, ocorrida a partir da década de 1990.
Nesse momento, a medicina científica ocidental passa por profundas mudanças no tocante a sua organização e práticas, dando origem à biomedicalização. Seu argumento central é que através da implementação de sistemas biomédicos, de informática e de ciências e tecnologias a biomedicina passou a intervir não só na saúde, na cura e na organização de cuidados médicos, como também na forma como pensamos e vivemos. As práticas de biomedicalização tomam como foco as transformações de fenômenos e de corpos através de intervenções tecnocientíficas dirigidas não somente para o tratamento, mas também para o aprimoramento da vida e para o risco. Um arcabouço de instituições biomédicas passa a ser então organizado, associado a práticas, tais como diagnósticos, tratamentos e intervenções ${ }^{19}$.

A existência desses diferentes estudos mostra a amplitude do conceito de medicalização ${ }^{1}$. O termo medicalização não reflete, pois, uma realidade, ou aspecto concreto e mensurável, caracterizando-se como uma categoria analítica, cuja utilização sofre influências diversas tais como: a ideológica, a política, assim como o aporte técnico que está sendo usado na análise. Como um conceito central ao estudo das relações medicina sociedade, a análise de seu emprego pode jogar luz nas diferentes concepções que embasam os conhecimentos e práticas no campo da saúde

\section{Método}

O estudo caracteriza-se como uma revisão narrativa da literatura. A pesquisa teve início com a busca por artigos publicados entre os anos de 2000, ano de criação do Programa de Humanização no Pré-natal e Nascimento (PHPN) ${ }^{4,7}$ e 2017 e indexados em três bases de dados. LILACS e MEDLINE busca feita através do portal da Biblioteca Virtual em Saúde (BVS) e SciELO feita na própria base. Foram utilizadas, para a busca dos artigos, as palavras e expressões: assistência ao parto, humanização do parto, trabalho de parto, parto e medicalização. Na LILACS e MEDLINE foram pesquisados tanto como descritores, quanto como palavras contidas no título, resumo e assunto. Na SciELO, tendo em vista as opções de busca encontradas na base de dados, foram pesquisadas como palavras e expressões contidas no título e resumo. As buscas geraram uma lista de 148.384 artigos. Com o auxílio dos filtros: Brasil como assunto; idioma português e artigo como tipo de documento, a seleção se reduziu para 5.153 artigos, como demonstrado no Figura 1. 
Palavras e expressões utilizadas na busca no período entre 2000 e 2017, segundo bases de dados ( $n=148.384)$

\begin{tabular}{|c|c|c|c|c|c|}
\hline $\begin{array}{c}\text { Bases de } \\
\text { dados }\end{array}$ & Medicalização & $\begin{array}{c}\text { Assistência ao } \\
\text { parto }\end{array}$ & $\begin{array}{c}\text { Humanizalçao do } \\
\text { parto }\end{array}$ & $\begin{array}{c}\text { Trabalho de } \\
\text { parto }\end{array}$ & Parto \\
\hline $\begin{array}{c}\text { MedLine } \\
(124.610)\end{array}$ & 458 & 15.266 & 06 & 24.634 & 84.246 \\
\hline $\begin{array}{c}\text { LILACS } \\
(14.337)\end{array}$ & 558 & 1.573 & 513 & 2.134 & 9.599 \\
\hline $\begin{array}{c}\text { SciElo } \\
(9.397)\end{array}$ & 444 & 618 & 139 & 975 & 7.221 \\
\hline
\end{tabular}

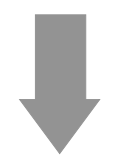

Primeira seleção: Brasil como assunto; idioma português e artigo como tipo de documento ( $\mathrm{n}=5.153)$

\begin{tabular}{|c|c|c|c|c|c|}
\hline $\begin{array}{c}\text { Bases de } \\
\text { dados }\end{array}$ & Medicalização & $\begin{array}{c}\text { Assistência ao } \\
\text { parto }\end{array}$ & $\begin{array}{c}\text { Humanizalçao do } \\
\text { parto }\end{array}$ & $\begin{array}{c}\text { Trabalho de } \\
\text { parto }\end{array}$ & Parto \\
\hline $\begin{array}{c}\text { MedLine } \\
(277)\end{array}$ & 16 & 38 & 04 & 25 & 194 \\
\hline $\begin{array}{c}\text { LILACS } \\
(1.067)\end{array}$ & 64 & 228 & 65 & 109 & 601 \\
\hline $\begin{array}{c}\text { SciElo } \\
(3.809)\end{array}$ & 203 & 325 & 69 & 556 & 2.656 \\
\hline
\end{tabular}

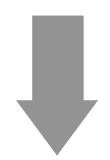

Seleção dos artigos através dos títulos e resumos, mantidos os que estavam associados diretamente à temática de interesse (excluídos aqueles que tratavam das áreas de parto prematuro, aleitamento, puerpério, aids, sífilis, parto de animais $)(\mathrm{n}=471)$

\begin{tabular}{|c|c|c|c|c|c|}
\hline $\begin{array}{c}\text { Bases de } \\
\text { dados }\end{array}$ & Medicalização & $\begin{array}{c}\text { Assistência ao } \\
\text { parto }\end{array}$ & $\begin{array}{c}\text { Humanizalçao do } \\
\text { parto }\end{array}$ & $\begin{array}{c}\text { Trabalho de } \\
\text { parto }\end{array}$ & Parto \\
\hline $\begin{array}{c}\text { MedLine } \\
(34)\end{array}$ & 0 & 8 & 1 & 2 & 23 \\
\hline $\begin{array}{c}\text { LILACS } \\
\text { (108) }\end{array}$ & 7 & 34 & 29 & 8 & 30 \\
\hline $\begin{array}{c}\text { SciElo } \\
(329)\end{array}$ & 7 & 70 & 25 & 57 & 170 \\
\hline \multicolumn{7}{|r}{}
\end{tabular}

Excluídas as repetições (268), foram lidos os textos completos de 203 artigos

Excluídos 100 artigos em que a palavra medicalização foi apenas citada sem realização de qualquer análise ou explicação do conceito

Figura 1. Fluxograma do processo de seleção dos artigos.

Fonte: Elaboração própria. 
Com a leitura dos títulos e resumos foi realizada uma etapa de seleção dos artigos que estavam associados diretamente à temática de interesse, sendo excluídos, por exemplo, aqueles que tratavam das áreas de parto prematuro, aleitamento, puerpério, aids, sífilis, parto de animais. Com esse procedimento chegamos ao número de 471 artigos. A seguir agrupamos os artigos selecionados em uma tabela única, excluímos as repetições e chegamos ao número de 203 artigos.

Procedemos a uma primeira leitura dos textos completos dos artigos para uma visão geral do tratamento dado à temática e para confirmação do corpus da investigação. Nesta etapa foram excluídos 100 artigos em que a palavra medicalização foi apenas citada sem realização de qualquer análise ou explicação do conceito. Assim, o resultado final ficou em 103 publicações que foram organizadas por título, autoria, periódico e ano de publicação e são apresentadas no Quadro 1. A seleção e organização dos artigos foi realizada pelo primeiro autor e nos casos de dúvida ou compartilhamento do andamento do processo foram realizadas reuniões com todos os autores.

Finalizada essa etapa, todos os autores integraram o processo de leitura aprofundada analisando as publicações a luz das perspectivas analíticas de medicalização e procurando responder ao seguinte questionamento: como os artigos que analisam a assistência ao parto no Brasil concebem o conceito de medicalização?

No processo de análise foram construídas cinco categorias, com base nos sentidos que foram mais recorrentes: a) Medicalização e intervenções no parto; b) Medicalização do parto e disputa profissional; c) Medicalização do parto e violação de direitos das gestantes; d) Medicalização e cenário do parto; e) Medicalização do parto como reflexo da medicalização da sociedade.

\section{Resultados e discussão}

\section{Medicalização e intervenções}

De forma predominante os artigos utilizam o conceito de medicalização relacionando-o ao modelo hegemônico de assistência ao trabalho de parto e ao parto, caracterizado como excessivamente intervencionista $(\mathrm{n}=74) \mathrm{I}-\mathrm{VIII}, \mathrm{X}-\mathrm{XI}$, XIV-XVI，XVIII，XX-XII，XXIV-XXVI，XXIX, XXXI, XXXIII-XLIII, XLV-L, LII, LV, LVIII-LIX, LXI-LXIII, LXVI, LXIX-LXXII, LXXIV, LXXVII -LXXXI, LXXXIV-LXXXVIII, XC-XCV, XCVII, XCIX-CI, CIII (Quadro 1) e acionam essa rela- ção quando a intenção é refletir criticamente sobre a medicalização em que se nota a ênfase dada aos aspectos negativos relacionados ao modelo. Nesses artigos é recomendada a substituição do modelo medicalizado por outro que recebe a denominação de humanizado. Sobre essa perspectiva encontramos duas tendências: uma que sugere um controle sobre práticas excessivas de medicalização, e outra que propõe uma ruptura com o modelo medicalizado $(\mathrm{n}=04) \mathrm{IX}, \mathrm{XXXV}$, XLIII, LXXV (Quadro 1). Alguns deles apresentam as duas propostas.

No que se refere aos casos em que a crítica ao modelo medicalizado se concentra nas práticas de excessiva medicalização, os artigos chamam atenção de que a utilização de procedimentos e tecnologias médicas na assistência ao parto tem sido realizada desvinculada das boas práticas. Nessas considerações são recorrentes as referências a procedimentos que quando são realizados de forma rotineira e sem base em evidências científicas podem causar resultados indesejáveis e prejudiciais tanto para a mãe quanto para o bebê. Esta posição se vincula as recomendações $\mathrm{da} \mathrm{MBE}^{5,20}$ e também às concepções que afirmam que a ampliação da jurisdição médica sobre a vida se caracteriza como um problema, à medida que amplia a iatrogenia ${ }^{16}$ :

(...) Durante a evolução do parto não se observa a sua fisiologia, buscando-se, constantemente, correçães do processo por meio da medicalização e do uso de intervenções que provocam consequências negativas sobre a saúde de mães e bebês ${ }^{21}$ (p.1062).

Alguns artigos $(\mathrm{n}=45)$ I, III, V, VII-VIII, X, XIV, XVI-XXII, XXIV-XXV, XXVII-XXIX, XXXI-XXXIII, XXXV-XXXVI, XL-XLI, XLIV, L, LII-LIV, LVI, LVIII-LIX, LXXI-LXXII, LXXV, LXXIX, LXXXVII, XCII, XCV, XCVII, XCIX-C, CIII (Quadro 1) chamam atenção de que o modelo medicalizado teria promovido o distanciamento da compreensão do parto como um evento natural e fisiológico, apresentando o enfoque humanista como aquele que permitiria o seu resgate.

Em um número menos expressivo, alguns artigos afirmam que não poderiam ser descartados benefícios trazidos por essa medicalização. Essa posição foi defendida em artigos que consideraram o uso de procedimentos medicalizados relevantes para proporcionar um parto mais seguro e em especial em artigos que concentraram suas análises em torno da analgesia de parto, que nesses casos é vista como estratégia de parto humanizado. As análises sobre a analgesia discorrem sobre a necessidade de minimizar a dor e de pro- 
Quadro 1. Artigos analisados $(\mathrm{n}=103)$.

\begin{tabular}{|c|c|c|c|c|}
\hline & Título & $1^{\circ}$ Autor & Periódico & Ano \\
\hline I & Assistência ao parto normal no domicílio & $\begin{array}{l}\text { Davim, Rejane } \\
\text { Marie Barbosa }\end{array}$ & $\begin{array}{l}\text { Rev Lat Am } \\
\text { Enfermagem }\end{array}$ & 2001 \\
\hline II & $\mathrm{O}$ anestesiologista no parto humanizado & $\begin{array}{l}\text { Chaves, Itagyba } \\
\text { Martins Miranda }\end{array}$ & CLASA & 2002 \\
\hline III & $\begin{array}{l}\text { Armadilhas da Nova Era: natureza e maternidade no } \\
\text { ideário da humanização do parto }\end{array}$ & $\begin{array}{l}\text { Tornquist, Carmen } \\
\text { Susana }\end{array}$ & Rev Estud Fem & 2002 \\
\hline IV & $\begin{array}{l}\text { Elementos constitutivos da formação e inserção de } \\
\text { profissionais não-médicos na assistência ao parto }\end{array}$ & $\begin{array}{l}\text { Riesco, Maria } \\
\text { Luiza Gonzalez } \\
\end{array}$ & $\begin{array}{l}\text { Cad Saude } \\
\text { Publica }\end{array}$ & 2002 \\
\hline $\mathrm{V}$ & $\begin{array}{l}\text { Parturiente e equipe obstétrica: a difícil arte da } \\
\text { comunicação }\end{array}$ & $\begin{array}{l}\text { Caron, Olga } \\
\text { Aparecida } \\
\text { Fortunato } \\
\end{array}$ & $\begin{array}{l}\text { Rev Lat Am } \\
\text { Enfermagem }\end{array}$ & 2002 \\
\hline VI & Tipo de parto: expectativas das mulheres & $\begin{array}{l}\text { Oliveira, Sonia } \\
\text { Maria Junqueira } \\
\text { Vasconcellos de }\end{array}$ & $\begin{array}{l}\text { Rev Lat Am } \\
\text { Enfermagem }\end{array}$ & 2002 \\
\hline VII & $\begin{array}{l}\text { A participação da enfermeira no processo de } \\
\text { desmedicalização do parto }\end{array}$ & $\begin{array}{l}\text { Progianti, Jane } \\
\text { Márcia }\end{array}$ & $\begin{array}{l}\text { Rev Enferm } \\
\text { UERJ }\end{array}$ & 2003 \\
\hline VIII & $\begin{array}{l}\text { Paradoxos da humanização em uma maternidade } \\
\text { no Brasil }\end{array}$ & $\begin{array}{l}\text { Tornquist, Carmen } \\
\text { Susana }\end{array}$ & $\begin{array}{l}\text { Cad Saude } \\
\text { Publica }\end{array}$ & 2003 \\
\hline IX & $\begin{array}{l}\text { O processo de desmedicalização da assistência à } \\
\text { mulher no ensino de enfermagem }\end{array}$ & $\begin{array}{l}\text { Vargens, Octavio } \\
\text { Muniz da Costa }\end{array}$ & $\begin{array}{l}\text { Rev Esc Enferm } \\
\text { USP }\end{array}$ & 2004 \\
\hline $\mathrm{X}$ & $\begin{array}{l}\text { A ótica de gestores sobre a humanização da } \\
\text { assistência nas maternidades municipais do Rio de } \\
\text { Janeiro }\end{array}$ & $\begin{array}{l}\text { Deslandes, Sueli } \\
\text { Ferreira }\end{array}$ & $\begin{array}{l}\text { Cien Saude } \\
\text { Colet }\end{array}$ & 2005 \\
\hline $\mathrm{XI}$ & $\begin{array}{l}\text { Desafios na implantação de uma política de } \\
\text { humanização da assistência hospitalar ao parto }\end{array}$ & $\begin{array}{l}\text { Dias, Marcos } \\
\text { Augusto Bastos }\end{array}$ & $\begin{array}{l}\text { Cien Saude } \\
\text { Colet }\end{array}$ & 2005 \\
\hline XII & $\begin{array}{l}\text { Evidências sobre o suporte durante o trabalho de } \\
\text { parto/parto: uma revisão da literatura }\end{array}$ & $\begin{array}{l}\text { Brüggemann, } \\
\text { Odaléa Maria }\end{array}$ & $\begin{array}{l}\text { Cad Saude } \\
\text { Publica }\end{array}$ & 2005 \\
\hline XIII & $\begin{array}{l}\text { Fatores interferentes no comportamento das } \\
\text { parturientes: enfoque na etnoenfermagem }\end{array}$ & $\begin{array}{l}\text { Bezerra, Maria } \\
\text { Gorette Andrade }\end{array}$ & Rev Bras Enferm & 2005 \\
\hline XIV & $\begin{array}{l}\text { Medicalização x humanização: o cuidado ao parto } \\
\text { na história }\end{array}$ & $\begin{array}{l}\text { Seibert, Sabrina } \\
\text { Lins }\end{array}$ & $\begin{array}{l}\text { Rev Enferm } \\
\text { UERJ }\end{array}$ & 2005 \\
\hline $\mathrm{XV}$ & $\begin{array}{l}\text { O pai no parto e apoio emocional: a perspectiva da } \\
\text { parturiente }\end{array}$ & $\begin{array}{l}\text { Motta, Cibele } \\
\text { Cunha Lima da }\end{array}$ & $\begin{array}{l}\text { Paidéia } \\
\text { (Ribeirão Preto) }\end{array}$ & 2005 \\
\hline XVI & $\begin{array}{l}\text { Parto humanizado na percepção das enfermeiras } \\
\text { obstétricas envolvidas com a assistência ao parto }\end{array}$ & $\begin{array}{l}\text { Castro, Jamile } \\
\text { Claro de }\end{array}$ & $\begin{array}{l}\text { Rev Lat Am } \\
\text { Enfermagem }\end{array}$ & 2005 \\
\hline XVII & $\begin{array}{l}\text { Percepção da dor pela mulher no pré-parto: a } \\
\text { influência do ambiente }\end{array}$ & $\begin{array}{l}\text { Macedo, Priscila } \\
\text { de Oliveira }\end{array}$ & $\begin{array}{l}\text { Rev Enferm } \\
\text { UERJ }\end{array}$ & 2005 \\
\hline XVIII & $\begin{array}{l}\text { Qualidade da atenção ao parto em maternidades do } \\
\text { Rio de Janeiro }\end{array}$ & D’Orsi, Eleonora & \begin{tabular}{|l|} 
Rev Saude \\
Publica
\end{tabular} & 2005 \\
\hline XIX & $\begin{array}{l}\text { A prática do parto humanizado no SUS: estudo } \\
\text { comparativo }\end{array}$ & $\begin{array}{l}\text { Wrobel, Luciele de } \\
\text { Lima }\end{array}$ & $\begin{array}{l}\text { Acta Sci, Health } \\
\text { Sci }\end{array}$ & 2006 \\
\hline $\mathrm{XX}$ & $\begin{array}{l}\text { A percepção dos acadêmicos de enfermagem } \\
\text { sobre o cuidado à mulher no trabalho de parto e } \\
\text { nascimento: uma abordagem qualitativa }\end{array}$ & Bicchieri, Thiago & $\begin{array}{l}\text { Esc Anna Nery } \\
\text { Rev Enferm }\end{array}$ & 2006 \\
\hline XXI & $\begin{array}{l}\text { Expectativas sobre a assistência ao parto de mulheres } \\
\text { usuárias de uma maternidade pública do Rio de } \\
\text { Janeiro, Brasil: os desafios de uma política pública de } \\
\text { humanização da assistência }\end{array}$ & $\begin{array}{l}\text { Dias, Marcos } \\
\text { Augusto Bastos }\end{array}$ & $\begin{array}{l}\text { Cad Saude } \\
\text { Publica }\end{array}$ & 2006 \\
\hline XXII & $\begin{array}{l}\text { Mulheres e profissionais de saúde: o imaginário } \\
\text { cultural na humanização ao parto e nascimento }\end{array}$ & $\begin{array}{l}\text { Griboski, Rejane } \\
\text { Antonello }\end{array}$ & $\begin{array}{l}\text { Texto Contexto } \\
\text { Enferm }\end{array}$ & 2006 \\
\hline XXIII & $\begin{array}{l}\text { Parto hospitalar: experiências de mulheres da } \\
\text { periferia de Cuiabá-MT }\end{array}$ & $\begin{array}{l}\text { Teixeira, Neuma } \\
\text { Zamariano Fanaia }\end{array}$ & Rev Bras Enferm & 2006 \\
\hline XXIV & $\begin{array}{l}\text { A crioterapia como estratégia para alívio da dor no } \\
\text { trabalho de parto: um estudo exploratório }\end{array}$ & Nunes, Sonia & $\begin{array}{l}\text { Rev Enferm } \\
\text { UERJ }\end{array}$ & 2007 \\
\hline
\end{tabular}


Quadro 1. Artigos analisados $(\mathrm{n}=103)$.

\begin{tabular}{|c|c|c|c|c|}
\hline & Título & 10 Autor & Periódico & Ano \\
\hline XXV & $\begin{array}{l}\text { A vivência de mulheres no parto domiciliar e } \\
\text { hospitalar }\end{array}$ & $\begin{array}{l}\text { Crizóstomo, } \\
\text { Cilene Delgado }\end{array}$ & $\begin{array}{l}\text { Esc Anna Nery } \\
\text { Rev Enferm }\end{array}$ & 2007 \\
\hline XXVI & Episiotomia: em foco a visão das mulheres & $\begin{array}{l}\text { Previatti, Jaqueline } \\
\text { Fátima }\end{array}$ & Rev Bras Enferm & 2007 \\
\hline XXVII & $\begin{array}{l}\text { Parto natural, normal e humanizado: termos } \\
\text { polissêmicos }\end{array}$ & \begin{tabular}{|l|} 
Dutra, Ivete \\
Lourdes
\end{tabular} & $\begin{array}{l}\text { Rev Gaucha } \\
\text { Enferm }\end{array}$ & 2007 \\
\hline XXVIII & $\begin{array}{l}\text { Pesquisa acadêmica sobre humanização do parto no } \\
\text { Brasil: tendências e contribuições }\end{array}$ & $\begin{array}{l}\text { Pereira, Adriana } \\
\text { Lenho de } \\
\text { Figueiredo } \\
\end{array}$ & $\begin{array}{l}\text { Acta Paul } \\
\text { Enferm }\end{array}$ & 2007 \\
\hline XXIX & $\begin{array}{l}\text { Reflexões sobre deambulação e posição materna no } \\
\text { trabalho de parto e parto }\end{array}$ & $\begin{array}{l}\text { Mamede, Fabiana } \\
\text { Villela }\end{array}$ & $\begin{array}{l}\text { Esc Anna Nery } \\
\text { Rev Enferm }\end{array}$ & 2007 \\
\hline $\mathrm{XXX}$ & $\begin{array}{l}\text { Vitalidade do recém-nascido por tipo de parto no } \\
\text { Estado de São Paulo, Brasil }\end{array}$ & Kilsztajn, Samuel & $\begin{array}{l}\text { Cad Saude } \\
\text { Publica }\end{array}$ & 2007 \\
\hline XXXI & $\begin{array}{l}\text { A escolha pelo parto domiciliar: história de vida de } \\
\text { mulheres que vivenciaram esta experiência }\end{array}$ & $\begin{array}{l}\text { Medeiros, Renata } \\
\text { Medeiros Knupp }\end{array}$ & $\begin{array}{l}\text { Esc Anna Nery } \\
\text { Rev Enferm }\end{array}$ & 2008 \\
\hline XXXII & $\begin{array}{l}\text { A negociação do cuidado de enfermagem obstétrica } \\
\text { através das práticas educativas na casa de Parto }\end{array}$ & $\begin{array}{l}\text { Progianti, Jane } \\
\text { Márcia }\end{array}$ & $\begin{array}{l}\text { Esc Anna Nery } \\
\text { Rev Enferm }\end{array}$ & 2008 \\
\hline XXXIII & $\begin{array}{l}\text { As tecnologias de cuidado de enfermagem obstétrica } \\
\text { fundamentas pela teoria ambientalista de Florence } \\
\text { Nightingale }\end{array}$ & $\begin{array}{l}\text { Macedo, Priscila } \\
\text { de Oliveira }\end{array}$ & $\begin{array}{l}\text { Esc Anna Nery } \\
\text { Rev Enferm }\end{array}$ & 2008 \\
\hline XXXIV & $\begin{array}{l}\text { Fatores médicos e não-médicos associados às taxas } \\
\text { de cesariana em um hospital universitário no Sul do } \\
\text { Brasil }\end{array}$ & $\begin{array}{l}\text { Freitas, Paulo } \\
\text { Fontoura }\end{array}$ & $\begin{array}{l}\text { Cad Saude } \\
\text { Publica }\end{array}$ & 2008 \\
\hline XXXV & $\begin{array}{l}\text { O significado da desmedicalização da assistência } \\
\text { ao parto no hospital: análise da concepção de } \\
\text { enfermeiras obstétricas. }\end{array}$ & $\begin{array}{l}\text { Vargens, Octavio } \\
\text { Muniz da Costa }\end{array}$ & $\begin{array}{l}\text { Rev Esc Enferm } \\
\text { USP }\end{array}$ & 2008 \\
\hline XXXVI & $\begin{array}{l}\text { Relações de hegemonia e o conflito cultural de } \\
\text { modelos na assistência ao parto }\end{array}$ & $\begin{array}{l}\text { Pereira, Adriana } \\
\text { Lenho de } \\
\text { Figueiredo } \\
\end{array}$ & $\begin{array}{l}\text { Rev Enferm } \\
\text { UERJ }\end{array}$ & 2008 \\
\hline XXXVII & $\begin{array}{l}\text { A acupuntura na analgesia do parto: percepções das } \\
\text { parturientes }\end{array}$ & $\begin{array}{l}\text { Martini, Jussara } \\
\text { Gue }\end{array}$ & $\begin{array}{l}\text { Esc Anna Nery } \\
\text { Rev Enferm }\end{array}$ & 2009 \\
\hline XXXVIII & $\begin{array}{l}\text { A arte de partejar: experiência de cuidado das } \\
\text { parteiras tradicionais de Envira/AM. }\end{array}$ & $\begin{array}{l}\text { Nascimento, Keila } \\
\text { Cristiane do }\end{array}$ & $\begin{array}{l}\text { Esc Anna Nery } \\
\text { Rev Enferm }\end{array}$ & 2009 \\
\hline XXXIX & $\begin{array}{l}\text { Aspectos relacionados à escolha do tipo de parto: } \\
\text { um estudo comparativo entre uma maternidade } \\
\text { pública e outra privada, em São Luís, Maranhão, } \\
\text { Brasil }\end{array}$ & $\begin{array}{l}\text { Mandarino, } \\
\text { Natália Ribeiro }\end{array}$ & $\begin{array}{l}\text { Cad Saude } \\
\text { Publica }\end{array}$ & 2009 \\
\hline XL & $\begin{array}{l}\text { Atenção ao parto por enfermeiros na Zona Leste do } \\
\text { município de São Paulo }\end{array}$ & $\begin{array}{l}\text { Narchi, Nádia } \\
\text { Zanon }\end{array}$ & Rev Bras Enferm & 2009 \\
\hline XLI & $\begin{array}{l}\text { Estratégias de luta das enfermeiras da Maternidade } \\
\text { Leila Diniz para implantação de um modelo } \\
\text { humanizado de assistência ao parto }\end{array}$ & $\begin{array}{l}\text { Mouta, Ricardo } \\
\text { José Oliveira }\end{array}$ & $\begin{array}{l}\text { Texto Contexto } \\
\text { Enferm }\end{array}$ & 2009 \\
\hline XLII & $\begin{array}{l}\text { Hegemonia e contra-hegemonia no processo de } \\
\text { implantação da Casa de Parto no Rio de Janeiro }\end{array}$ & $\begin{array}{l}\text { Pereira, Adriana } \\
\text { Lenho de } \\
\text { Figueiredo }\end{array}$ & $\begin{array}{l}\text { Rev Esc Enferm } \\
\text { USP }\end{array}$ & 2009 \\
\hline XLIII & $\begin{array}{l}\text { Humanização e desmedicalização da assistência à } \\
\text { mulher: do ensino à prática }\end{array}$ & $\begin{array}{l}\text { Moura, Carla } \\
\text { Fabíola Sampaio } \\
\text { de }\end{array}$ & $\begin{array}{l}\text { Rev Enferm } \\
\text { UERJ }\end{array}$ & 2009 \\
\hline XLIV & $\begin{array}{l}\text { O cuidado a saúde materna no Brasil e o resgate do } \\
\text { ensino de obstetrizes para assistência ao parto }\end{array}$ & $\begin{array}{l}\text { Merighi, Miriam } \\
\text { Aparecida Barbosa }\end{array}$ & $\begin{array}{l}\text { Rev Lat Am } \\
\text { Enfermagem }\end{array}$ & 2009 \\
\hline XLV & $\begin{array}{l}\text { Representações e experiências das mulheres } \\
\text { sobre a assistência ao parto vaginal e cesárea em } \\
\text { maternidades pública e privada }\end{array}$ & $\begin{array}{l}\text { Gama, Andréa de } \\
\text { Sousa }\end{array}$ & $\begin{array}{l}\text { Cad Saude } \\
\text { Publica }\end{array}$ & 2009 \\
\hline
\end{tabular}


Quadro 1. Artigos analisados $(\mathrm{n}=103)$.

\begin{tabular}{|c|c|c|c|c|}
\hline & Título & $1^{\circ}$ Autor & Periódico & Ano \\
\hline XLVI & $\begin{array}{l}\text { A influência da assistência profissional em saúde } \\
\text { na escolha do tipo de parto: um olhar sócio } \\
\text { antropológico na saúde suplementar brasileira }\end{array}$ & Pires, Denise & $\begin{array}{l}\text { Rev Bras Saude } \\
\text { Matern Infant }\end{array}$ & 2010 \\
\hline XLVII & $\begin{array}{l}\text { Análise do exercício de competências dos não } \\
\text { médicos para atenção à maternidade }\end{array}$ & $\begin{array}{l}\text { Narchi, Nádia } \\
\text { Zanon }\end{array}$ & Saude Soc & 2010 \\
\hline XLVIII & $\begin{array}{l}\text { Assistência ao parto na maternidade: representações } \\
\text { sociais de mulheres assistidas e profissionais de } \\
\text { saúde }\end{array}$ & $\begin{array}{l}\text { Silveira, Sandra } \\
\text { Cristina da }\end{array}$ & $\begin{array}{l}\text { Psicol Reflex } \\
\text { Crit }\end{array}$ & 2010 \\
\hline XLIX & $\begin{array}{l}\text { Expectativas de participação de gestantes e } \\
\text { acompanhantes para o parto humanizado }\end{array}$ & $\begin{array}{l}\text { Basso, Joéli } \\
\text { Fernanda }\end{array}$ & $\begin{array}{l}\text { Rev Lat Am } \\
\text { Enfermagem }\end{array}$ & 2010 \\
\hline $\mathrm{L}$ & $\begin{array}{l}\text { Resultados maternos e neonatais em Centro de } \\
\text { Parto Normal peri-hospitalar na cidade de São } \\
\text { Paulo, Brasil }\end{array}$ & $\begin{array}{l}\text { Lobo, Sheila } \\
\text { Fagundes }\end{array}$ & $\begin{array}{l}\text { Rev Esc Enferm } \\
\text { USP }\end{array}$ & 2010 \\
\hline LI & A dor e o protagonismo da mulher na parturição & $\begin{array}{l}\text { Pereira, Raquel da } \\
\text { Rocha }\end{array}$ & $\begin{array}{l}\text { Rev Bras } \\
\text { Anestesiol }\end{array}$ & 2011 \\
\hline LII & $\begin{array}{l}\text { A humanização do nascimento: percepção dos } \\
\text { profissionais de saúde que atuam na atenção ao } \\
\text { parto }\end{array}$ & $\begin{array}{l}\text { Souza, Taísa } \\
\text { Guimarães de }\end{array}$ & $\begin{array}{l}\text { Rev Gaucha } \\
\text { Enferm }\end{array}$ & 2011 \\
\hline LIII & $\begin{array}{l}\text { Cuidado e conforto no parto: estudos na } \\
\text { enfermagem brasileira }\end{array}$ & $\begin{array}{l}\text { Frello, Ariane } \\
\text { Thaise }\end{array}$ & $\begin{array}{l}\text { Rev Baiana } \\
\text { Enferm }\end{array}$ & 2011 \\
\hline LIV & $\begin{array}{l}\text { Estratégias dirigidas aos profissionais para a redução } \\
\text { das cesáreas desnecessárias no Brasil }\end{array}$ & $\begin{array}{l}\text { Haddad, Samira El } \\
\text { Maerrawi T }\end{array}$ & $\begin{array}{l}\text { Rev Bras Ginecol } \\
\text { Obstet }\end{array}$ & 2011 \\
\hline LV & $\begin{array}{l}\text { Movimentação e dieta durante o trabalho de parto: a } \\
\text { percepção de um grupo de puérperas }\end{array}$ & Wei, Chang Yi & $\begin{array}{l}\text { Texto Contexto } \\
\text { Enferm }\end{array}$ & 2011 \\
\hline LVI & $\begin{array}{l}\text { Ocorrência de episiotomia em partos acompanhados } \\
\text { por enfermeiros obstetras em ambiente hospitalar }\end{array}$ & $\begin{array}{l}\text { Figueiredo, Giselle } \\
\text { da Silva }\end{array}$ & $\begin{array}{l}\text { Rev Enferm } \\
\text { UERJ }\end{array}$ & 2011 \\
\hline LVII & $\begin{array}{l}\text { Representações sociais e decisões das gestantes sobre } \\
\text { a parturição: protagonismo das mulheres }\end{array}$ & $\begin{array}{l}\text { Pereira, Raquel da } \\
\text { Rocha }\end{array}$ & Saude Soc & 2011 \\
\hline LVIII & $\begin{array}{l}\text { A humanização da assistência ao parto na percepção } \\
\text { de estudantes de medicina }\end{array}$ & $\begin{array}{l}\text { Rebello, Maria } \\
\text { Tereza Maia } \\
\text { Penido }\end{array}$ & $\begin{array}{l}\text { Rev Bras Educ } \\
\text { Med }\end{array}$ & 2012 \\
\hline LIX & $\begin{array}{l}\text { Modelo humanizado de atenção ao parto no Brasil: } \\
\text { evidências na produção científica }\end{array}$ & $\begin{array}{l}\text { Gomes, Maysa } \\
\text { Luduvice }\end{array}$ & $\begin{array}{l}\text { Rev Enferm } \\
\text { UERJ } \\
\end{array}$ & 2012 \\
\hline LX & $\begin{array}{l}\text { O contexto brasileiro de inserção das enfermeiras na } \\
\text { assistência ao parto humanizado }\end{array}$ & $\begin{array}{l}\text { Prata, Juliana } \\
\text { Amaral }\end{array}$ & $\begin{array}{l}\text { Rev Enferm } \\
\text { UERJ }\end{array}$ & 2012 \\
\hline LXI & $\begin{array}{l}\text { O desencontro entre desejo e realidade: a indústria } \\
\text { da cesariana entre mulheres de camadas médias no } \\
\text { Rio de Janeiro, Brasil }\end{array}$ & $\begin{array}{l}\text { Cardoso, Junia } \\
\text { Espinha }\end{array}$ & Physis & 2012 \\
\hline LXII & $\begin{array}{l}\text { O processo de parir assistido pela enfermeira } \\
\text { obstétrica no contexto hospitalar: significados para } \\
\text { as parturientes }\end{array}$ & $\begin{array}{l}\text { Caus, Eliz Cristine } \\
\text { Maurer }\end{array}$ & $\begin{array}{l}\text { Esc Anna Nery } \\
\text { Rev Enferm }\end{array}$ & 2012 \\
\hline LXIII & $\begin{array}{l}\text { Perfil das mulheres submetidas à cesareana e } \\
\text { assistência obstétrica na maternidade pública em } \\
\text { Ribeirão Preto }\end{array}$ & $\begin{array}{l}\text { Sanches, Natália } \\
\text { Canella }\end{array}$ & $\begin{array}{l}\text { Texto Contexto } \\
\text { Enferm }\end{array}$ & 2012 \\
\hline LXIV & $\begin{array}{l}\text { Perspectivas de dor do parto normal de primigestas } \\
\text { no período pré-natal. }\end{array}$ & $\begin{array}{l}\text { Almeida, Nilza } \\
\text { Alves Marques }\end{array}$ & $\begin{array}{l}\text { Texto Contexto } \\
\text { Enferm }\end{array}$ & 2012 \\
\hline LXV & $\begin{array}{l}\text { Práticas educativas desenvolvidas por enfermeiras: } \\
\text { repercussões sobre vivências de mulheres na } \\
\text { gestação e no parto }\end{array}$ & $\begin{array}{l}\text { Progianti, Jane } \\
\text { Márcia }\end{array}$ & Rev Bras Enferm & 2012 \\
\hline LXVI & $\begin{array}{l}\text { Tendência temporal de partos cesáreos no Brasil e } \\
\text { suas Regiões: } 1994 \text { a } 2009\end{array}$ & $\begin{array}{l}\text { Hõfelmann, } \\
\text { Doroteia } \\
\text { Aparecida }\end{array}$ & $\begin{array}{l}\text { Epidemiol Serv } \\
\text { Saúde }\end{array}$ & 2012 \\
\hline LXVII & A construção cultural do processo de parto & $\begin{array}{l}\text { Pimenta, Lizandra } \\
\text { Flores }\end{array}$ & $\begin{array}{l}\text { Rev Pesqui Cuid } \\
\text { Fundam }\end{array}$ & 2013 \\
\hline
\end{tabular}


Quadro 1. Artigos analisados $(\mathrm{n}=103)$.

\begin{tabular}{|c|c|c|c|c|}
\hline & Título & $1^{\circ}$ Autor & Periódico & Ano \\
\hline LXVIII & $\begin{array}{l}\text { A percepção dos profissionais sobre a assistência ao } \\
\text { parto domiciliar planejado }\end{array}$ & $\begin{array}{l}\text { Frank, Tatiane } \\
\text { Cavalcante }\end{array}$ & $\begin{array}{l}\text { Rev Gaucha } \\
\text { Enferm }\end{array}$ & 2013 \\
\hline LXIX & $\begin{array}{l}\text { A prática obstétrica da enfermeira no parto } \\
\text { institucionalizado: uma possibilidade de } \\
\text { conhecimento emancipatório }\end{array}$ & $\begin{array}{l}\text { Gomes, Maysa } \\
\text { Luduvice }\end{array}$ & $\begin{array}{l}\text { Texto Contexto } \\
\text { Enferm }\end{array}$ & 2013 \\
\hline LXX & $\begin{array}{l}\text { Avaliação da qualidade da atenção ao trabalho de } \\
\text { parto e parto de adolescentes }\end{array}$ & $\begin{array}{l}\text { Vilarinho, Lílian } \\
\text { Machado }\end{array}$ & $\begin{array}{l}\text { Rev Enferm } \\
\text { UERJ }\end{array}$ & 2013 \\
\hline
\end{tabular}

\begin{tabular}{|c|c|c|c|c|}
\hline LXXI & $\begin{array}{l}\text { Equipe de enfermagem e os dispositivos de cuidado } \\
\text { no trabalho de parto: enfoque na humanização }\end{array}$ & $\begin{array}{l}\text { Souza, Camila } \\
\text { Maria de }\end{array}$ & $\begin{array}{l}\text { Rev Pesqui Cuid } \\
\text { Fundam }\end{array}$ & 2013 \\
\hline LXXII & $\begin{array}{l}\text { O papel das obstetrizes e enfermeiras obstetras na } \\
\text { promoção da maternidade segura no Brasil }\end{array}$ & $\begin{array}{l}\text { Narchi, Nádia } \\
\text { Zanon }\end{array}$ & $\begin{array}{l}\text { Cien Saude } \\
\text { Colet }\end{array}$ & 2013 \\
\hline LXXIII & $\begin{array}{l}\text { Processo de gestar e parir entre as mulheres } \\
\text { Kaingang }\end{array}$ & $\begin{array}{l}\text { Moliterno, Aline } \\
\text { Cardoso Machado }\end{array}$ & $\begin{array}{l}\text { Texto Contexto } \\
\text { Enferm }\end{array}$ & 2013 \\
\hline LXXIV & $\begin{array}{l}\text { Reflexões sobre o excesso de cesarianas no Brasil e a } \\
\text { autonomia das mulheres }\end{array}$ & $\begin{array}{l}\text { Leão, Míriam } \\
\text { Rêgo de Castro }\end{array}$ & $\begin{array}{l}\text { Cien Saude } \\
\text { Colet }\end{array}$ & 2013 \\
\hline LXXV & $\begin{array}{l}\text { A assistência humanizada no trabalho de parto: } \\
\text { percepção das adolescentes }\end{array}$ & $\begin{array}{l}\text { Vargas, Pricilla } \\
\text { Braga }\end{array}$ & $\begin{array}{l}\text { Rev Pesqui Cuid } \\
\text { Fundam }\end{array}$ & 2014 \\
\hline LXXVI & $\begin{array}{l}\text { A prática das enfermeiras obstétricas nas } \\
\text { emergências vinculadas ao Programa Cegonha } \\
\text { Carioca }\end{array}$ & $\begin{array}{l}\text { Progianti, Jane } \\
\text { Marcia }\end{array}$ & $\begin{array}{l}\text { Rev Enferm } \\
\text { UERJ }\end{array}$ & 2014 \\
\hline LXXVII & $\begin{array}{l}\text { A reestruturação produtiva na área da saúde e da } \\
\text { enfermagem obstétrica }\end{array}$ & $\begin{array}{l}\text { Prata, Juliana } \\
\text { Amaral }\end{array}$ & $\begin{array}{l}\text { Texto Contexto } \\
\text { Enferm }\end{array}$ & 2014 \\
\hline LXXVIII & $\begin{array}{l}\text { Atendimento prestado a parturiente em um hospital } \\
\text { universitário }\end{array}$ & $\begin{array}{l}\text { Silva, Francisca } \\
\text { Francineide } \\
\text { Andrade da } \\
\end{array}$ & $\begin{array}{l}\text { Rev Pesqui Cuid } \\
\text { Fundam }\end{array}$ & 2014 \\
\hline LXXIX & Do parto institucionalizado ao parto domiciliar & $\begin{array}{l}\text { Sanfelice, Clara } \\
\text { Fróes de Oliveira } \\
\end{array}$ & Rev Rene & 2014 \\
\hline LXXX & $\begin{array}{l}\text { Comparação de modelos de assistência ao parto em } \\
\text { hospitais públicos }\end{array}$ & $\begin{array}{l}\text { Vogt, Sibylle } \\
\text { Emilie }\end{array}$ & $\begin{array}{l}\text { Rev Saude } \\
\text { Publica }\end{array}$ & 2014 \\
\hline LXXXI & $\begin{array}{l}\text { Informação para a opção pelo parto domiciliar } \\
\text { planejado: um direito de escolha das mulheres }\end{array}$ & $\begin{array}{l}\text { Lessa, Heloisa } \\
\text { Ferreira }\end{array}$ & $\begin{array}{l}\text { Texto Contexto } \\
\text { Enferm }\end{array}$ & 2014 \\
\hline LXXXII & $\begin{array}{l}\text { A normalização da cesárea como modo de nascer: } \\
\text { cultura material do parto em maternidades privadas } \\
\text { no Sudeste do Brasil }\end{array}$ & $\begin{array}{l}\text { Nakano, Andreza } \\
\text { Rodrigues }\end{array}$ & Physis & 2015 \\
\hline LXXXIII & $\begin{array}{l}\text { Inclusão de parteiras tradicionais no Sistema Único } \\
\text { de Saúde no Brasil: reflexão sobre desafios }\end{array}$ & $\begin{array}{l}\text { Gusman, Christine } \\
\text { Ranier }\end{array}$ & $\begin{array}{l}\text { Rev Panam } \\
\text { Salud Publica }\end{array}$ & 2015 \\
\hline LXXXIV & $\begin{array}{l}\text { Obstetrizes e enfermeiras obstetras no Sistema } \\
\text { Único de Saúde e na Atenção Primária à Saúde: por } \\
\text { uma incorporação sistêmica e progressiva }\end{array}$ & $\begin{array}{l}\text { Norman, } \\
\text { Armando } \\
\text { Henrique }\end{array}$ & $\begin{array}{l}\text { Rev Bras } \\
\text { Med Fam } \\
\text { Comunidade } \\
\end{array}$ & 2015 \\
\hline LXXXV & $\begin{array}{l}\text { Parto domiciliar: Compreendendo os motivos dessa } \\
\text { escolha }\end{array}$ & $\begin{array}{l}\text { Sanfelice, Clara } \\
\text { Fróes de Oliveira }\end{array}$ & $\begin{array}{l}\text { Texto Contexto } \\
\text { Enferm }\end{array}$ & 2015 \\
\hline LXXXVI & Representações sociais sobre o parto domiciliar & $\begin{array}{l}\text { Sanfelice, Clara } \\
\text { Fróes de Oliveira } \\
\end{array}$ & $\begin{array}{l}\text { Esc Anna Nery } \\
\text { Rev Enferm }\end{array}$ & 2015 \\
\hline LXXXVII & $\begin{array}{l}\text { Análise de partos acompanhados por enfermeiras } \\
\text { obstétricas na perspectiva da humanização do parto } \\
\text { e nascimento }\end{array}$ & $\begin{array}{l}\text { Reis, Carlos Sérgio } \\
\text { Corrêa dos }\end{array}$ & $\begin{array}{l}\text { Rev Pesqui Cuid } \\
\text { Fundam }\end{array}$ & 2016 \\
\hline LXXXVIII & $\begin{array}{l}\text { Assistência ao parto no Brasil: uma situação crítica } \\
\text { ainda não superada. 1999-2013 }\end{array}$ & $\begin{array}{l}\text { Silva, Ana Lucia } \\
\text { Andrade da }\end{array}$ & $\begin{array}{l}\text { Rev Bras Saude } \\
\text { Matern Infantil }\end{array}$ & 2016 \\
\hline LXXXIX & $\begin{array}{l}\text { Cesárea, aperfeiçoando a técnica e normatizando a } \\
\text { prática: uma análise do livro Obstetrícia, de Jorge de } \\
\text { Rezende }\end{array}$ & $\begin{array}{l}\text { Nakano, Andreza } \\
\text { Rodrigues }\end{array}$ & $\begin{array}{l}\text { Hist Cien Saude } \\
\text { Manguinhos }\end{array}$ & 2016 \\
\hline $\mathrm{XC}$ & $\begin{array}{l}\text { Fatores associados à violência obstétrica na } \\
\text { assistência ao parto vaginal em uma maternidade de } \\
\text { alta complexidade em Recife, Pernambuco }\end{array}$ & $\begin{array}{l}\text { Andrade, Priscyla } \\
\text { de Oliveira } \\
\text { Nascimento }\end{array}$ & $\begin{array}{l}\text { Rev Bras Saude } \\
\text { Matern Infant }\end{array}$ & 2016 \\
\hline
\end{tabular}


Quadro 1. Artigos analisados $(\mathrm{n}=103)$.

\begin{tabular}{|c|c|c|c|c|}
\hline & \begin{tabular}{|c|} 
Título \\
\end{tabular} & $1^{\circ}$ Autor & Periódico & Ano \\
\hline $\mathrm{XCI}$ & $\begin{array}{l}\text { Uso de práticas integrativas e complementares } \\
\text { por doulas em maternidades de Fortaleza (CE) e } \\
\text { Campinas (SP) }\end{array}$ & $\begin{array}{l}\text { Silva, Raimunda } \\
\text { Magalhães da }\end{array}$ & Saude Soc & 2016 \\
\hline XCII & $\begin{array}{l}\text { À margem da humanização? Experiências de parto } \\
\text { de usuárias de uma maternidade pública de Porto } \\
\text { Alegre-RS }\end{array}$ & $\begin{array}{l}\text { Pedroso, Clarissa } \\
\text { Niederauer Leote } \\
\text { da Silva }\end{array}$ & Physis & 2017 \\
\hline XCIII & $\begin{array}{l}\text { A qualidade do atendimento ao parto na rede } \\
\text { pública hospitalar em uma capital brasileira: a } \\
\text { satisfação das gestantes }\end{array}$ & $\begin{array}{l}\text { Silva, Ana Lúcia } \\
\text { Andrade da }\end{array}$ & $\begin{array}{l}\text { Cad Saude } \\
\text { Pública }\end{array}$ & 2017 \\
\hline XCIV & $\begin{array}{l}\text { Autonomia para quem? O discurso médico } \\
\text { hegemônico sobre a violência obstétrica no Brasil }\end{array}$ & $\begin{array}{l}\text { Palharini, Luciana } \\
\text { Aparecida }\end{array}$ & Cad Pagu & 2017 \\
\hline $\mathrm{XCV}$ & $\begin{array}{l}\text { Contribuição de enfermeiras obstétricas } \\
\text { para consolidação do parto humanizado em } \\
\text { maternidades no Rio de Janeiro-Brasil }\end{array}$ & $\begin{array}{l}\text { Vargens, Octavio } \\
\text { Muniz da Costa }\end{array}$ & $\begin{array}{l}\text { Esc Anna Nery } \\
\text { Rev Enferm }\end{array}$ & 2017 \\
\hline XCVI & $\begin{array}{l}\text { Fatores que influenciam a escolha do tipo de parto } \\
\text { na percepção das puérperas }\end{array}$ & $\begin{array}{l}\text { Feitosa, Rúbia } \\
\text { Mara Maia }\end{array}$ & $\begin{array}{l}\text { Rev Pesqui Cuid } \\
\text { Fundam }\end{array}$ & 2017 \\
\hline XCVII & $\begin{array}{l}\text { Grupos de gestantes: espaço para humanização do } \\
\text { parto e nascimento }\end{array}$ & $\begin{array}{l}\text { Matos, Greice } \\
\text { Carvalho de }\end{array}$ & $\begin{array}{l}\text { Rev Pesqui Cuid } \\
\text { Fundam }\end{array}$ & 2017 \\
\hline XCVIII & $\begin{array}{l}\text { Histórias de parto e a ultrassonografia como marco } \\
\text { narrativo no Rio de Janeiro }\end{array}$ & $\begin{array}{l}\text { Rezende, Claudia } \\
\text { Barcellos }\end{array}$ & $\begin{array}{l}\text { Sex Salud Soc } \\
\text { (Rio J) }\end{array}$ & 2017 \\
\hline XCIX & $\begin{array}{l}\text { Humanização do parto: significados e percepções de } \\
\text { enfermeiras }\end{array}$ & $\begin{array}{l}\text { Possati, Andrêssa } \\
\text { Batista }\end{array}$ & $\begin{array}{l}\text { Esc Anna Nery } \\
\text { Rev Enferm }\end{array}$ & 2017 \\
\hline $\mathrm{C}$ & $\begin{array}{l}\text { O cuidado à mulher no contexto da maternidade: } \\
\text { caminhos e desafios para a humanização }\end{array}$ & $\begin{array}{l}\text { Dodou, Hilana } \\
\text { Dayana }\end{array}$ & $\begin{array}{l}\text { Rev Pesqui Cuid } \\
\text { Fundam }\end{array}$ & 2017 \\
\hline $\mathrm{CI}$ & $\begin{array}{l}\text { O discurso da violência obstétrica na voz das } \\
\text { mulheres e dos profissionais de saúde }\end{array}$ & $\begin{array}{l}\text { Oliveira, Virgínia } \\
\text { Junqueira }\end{array}$ & $\begin{array}{l}\text { Texto Contexto } \\
\text { Enferm }\end{array}$ & 2017 \\
\hline CII & $\begin{array}{l}\text { Violência obstétrica no Brasil e o ciberativismo de } \\
\text { mulheres mães: relato de duas experiências }\end{array}$ & $\begin{array}{l}\text { Sena, Ligia } \\
\text { Moreiras }\end{array}$ & $\begin{array}{l}\text { Interface } \\
\text { (Botucatu) }\end{array}$ & 2017 \\
\hline CIII & Violência obstétrica no Brasil: uma revisão narrativa & $\begin{array}{l}\text { Zanardo, Gabriela } \\
\text { Lemos de Pinho }\end{array}$ & Psicol Soc & 2017 \\
\hline
\end{tabular}

Fonte: Elaboração própria.

porcionar um parto com maior conforto para a mãe. A proposta trazida por esses artigos aponta para a necessidade de adoção de um novo olhar para a técnica anestésica, superando a visão de que a analgesia estaria relacionada ao insucesso do parto vaginal:

A analgesia de parto é, sem dúvida, uma importante ferramenta para se atingir o objetivo de um parto hospitalar humanizado ${ }^{22}$.

Ainda nessa categoria alguns artigos fazem uso do termo "desmedicalização" ( $\mathrm{n}=21)$ VII, IX -XI, XVI, XXIV, XXXII, XXXV-XXXVI, XL, XLIII, LII-LIII, LIX, LXIX, LXXVII, LXXXI, LXXXVII, XCV, CII (Quadro 1) e observamos que a sua utilização, assim como percebido no uso do conceito de medicalização, agrega diferentes sentidos.

Conformando a tendência de necessidade de ruptura com o modelo medicalizado nos 04 arti- gos já referenciados anteriormente, essa ruptura por vezes aparece expressa através da antítese: "medicalização x humanização" ${ }^{23}$, ou como verificado no trecho a seguir:

A humanização da assistência obstétrica vem sendo implementada como uma filosofia de trabatho visando um maior conforto fisico e mental para as mães e também para os bebês, pois trará vários benefícios para ambos, e rompendo como a medicalização do parto, utilização de práticas em saúde sem a comprovação de seu benefício, além do resgate da mulher como figura principal do processo parturitivo $^{24}$ (p.1022).

Em relação à categoria como um todo, observou-se a pouca interação com as reflexões já existentes sobre o conceito de medicalização, uma vez que somente em 11 artigos VII, IX-X, XVI, XXXV-XXXVI, LXXIV, XCI-XCII, XCIV, 


\section{Medicalização e disputa profissional}

Considerando-se o total dos 103 artigos analisados, 41 deles IV, VII, IX, XI, XV-XVI, XVIII, XXII, XXVII, XXIX-XXX, XXXII, XXXV, XL-XLIV, XLVIII, L, LVI, LX-LXI, LXIII-LXVII, LXIX, LXXI-LXXII, LXXVII, LXXIX, LXXXI, LXXXIV, XCI. XCIV-XCV, C-CI, CIII (Quadro 1) apresentam o conceito de medicalização como uma prática conduzida pelo profissional médico, identificado como o agente que tomou para si o poder de condução dos cuidados de saúde, entre os quais se incluem os partos. Segundo esses trabalhos, os saberes e as práticas dos médicos teriam imposto condutas que desqualificam o protagonismo das mulheres no processo de trabalho de parto e parto, sendo esse profissional o responsável por condutas prejudiciais e desumanizantes de assistência:

O processo de medicalização é, também, relacionado ao poder simbólico que os profissionais médicos detêm, e que é o poder de fazer ver e fazer crer, impondo uma visão e o reconhecimento desse poder, que passa a ser visto como natural, tanto por quem exerce o poder como por quem a ele está submetido ${ }^{8}$, reforçando a hegemonia desses profissionais no campo da saúde, queé, também, um campo $\operatorname{social}^{25}(\mathrm{p} .183)$.

Em resposta às críticas à atuação do médico, a indicação da sua substituição pelo profissional de enfermagem, mais especificamente a enfermeira obstétrica ou a obstetriz foi recorrente, e frequentemente associada a propostas de humanização da assistência.

Nesse grupo de artigos o termo desmedicalizar assume um sentido relacionado à retirada do profissional médico da cena e dos cuidados relativos ao trabalho de parto e parto, posição por vezes vinculada à posição apresentada pela Organização Mundial da Saúde e pelo Ministério da Saúde brasileiro, de reconhecimento da importância da atuação da enfermagem entre as profissões de saúde como agente desmedicalizante ${ }^{25}$.

Alguns artigos chegam a afirmar que a enfermeira obstétrica seria a única profissional não médica que poderia ser associada a uma possi- bilidade de resgate do parto fisiológico em que a mulher atuasse como protagonista, e única verdadeiramente comprometida com o modelo humanizado ${ }^{26}$ :

Assim, muitos profissionais são adeptos do cuidado medicalizado e freqüentemente fazem uso de intervenções no cuidado ao parto. Outros, como é o caso das enfermeiras, superaram este modelo de assistência e desenvolvem habilidades não invasivas que são peculiares do modelo humanizado feminino e desmedicalizado de assistência ao parto.

No contexto atual, a enfermeira obstétrica é a única profissional não médica que tem sido associada com um saber/fazer que vem ao encontro da possibilidade de resgatar o parto fisiológico como um fenômeno feminino onde a mulher seja a protagonista ${ }^{(2)}$. Deste modo, esta profissional vem contribuindo para a consolidação do modelo humanizado de assistência ao parto que necessariamente passa pelo cuidado desmedicalizado ${ }^{(3)} \cdot{ }^{26}(\mathrm{p} \cdot 340)$.

Em contraposição à proposição de que as enfermeiras seriam as únicas profissionais capazes de protagonizar um modelo de parto humanizado, encontramos artigos que indicam que apenas a substituição de uma categoria profissional por outra, não se configuraria como garantia de mudanças no modelo assistencial:

Pela análise dos obstáculos relatados, observa-se que os enfermeiros estão alinhados com os preceitos da humanização da assistência ao parto, sendo, todavia, impedidos institucional ou profissionalmente a fazê-lo. Entretanto, a descrição da atenção em cada um dos hospitais e a análise das atividades assinaladas mostrou que eles também são responsáveis pela medicalização do parto na medida em que utilizam práticas tradicionais e desaconselhadas pelas evidências científicas, muitas delas prejudiciais à saúde materna e perinatal, conforme exposto ${ }^{27}$ (p.550).

Nesse prisma analítico, as afirmações apresentadas se aproximam do conceito de medicalização entendido como processo heterogêneo e marcado por interesses múltiplos e de caráter irregular, entre os quais aqueles relacionados à concorrência interprofissional. Sem encontrarmos referências literais, o sentido desenvolvido nesta categoria nos remete as análises realizadas por Peter Conrad ${ }^{18}$.

\section{Medicalização e violação de direitos das gestantes}

Vários artigos entendem a medicalização como um processo que envolve diferentes formas de violação de direitos, dentre os quais os 
que se relacionam ao trato entre os profissionais e as mulheres $(n=37)$ III, VII-IX, XI, XIV, XIX-XXIII, XXXI-XXXII, XXXVI, XL, XLIII, XLV-XLVII, XLIX, LII-LIII, LVIII-LIX, LXI, LXVII, LXX, LXXII, LXXIV, LXXVIII, XCII, XCIV, XCVI-XCVII, XCIX, CII-CIII (Quadro 1). Embora tenha sido encontrada menção a formas de violação dos direitos, tanto em relação às mulheres, quanto aos bebês e as famílias, de forma majoritária, os artigos detiveram suas análises na apreciação da violação de direitos das mulheres, especialmente no que tange aos cuidados que valorizam o uso excessivo de tecnologias em detrimento da intersubjetividade que deveria embasar as relações entre os sujeitos que compõem a cena do parto:

Com isso, o tratamento humilhante nos serviços de saúde, o abuso na medicalização dos partos, as intervenções cirúrgicas desnecessárias, a falta de acesso aos leitos e a desinformação passaram a ser considerados como desrespeito aos direitos reprodutivos e sexuais das mulheres e, consequentemente, violações aos direitos humanos, passando, também, a serem entendidos como práticas e modelos desumanizantes de assistência à mulher e a sua família ${ }^{6}{ }^{25}$ (p.183).

Compreendemos que esse processo de violação de direitos compõe o quadro que recentemente tem sido nomeado como "violência obstétrica" em referência a diversas formas de abusos, desrespeito e constrangimento sofridos pela mulher durante o parto, gravidez, pós-parto e abortamento ${ }^{28}$.

Nessa categoria mais uma vez encontramos a utilização do termo desmedicalizado como expressão de crítica e superação do modelo medicalizado, e sua substituição por outro nomeado como humanizado, agora empregado no sentido de possibilitar a mulher o protagonismo em relação às decisões que envolvem a assistência ao parto.

Algumas análises propõem que o deslocamento do conhecimento feminino sobre o partejar para o conhecimento médico se configura como um processo de violação de direitos das mulheres. Contudo, também foram encontradas considerações de que o curso desse processo de medicalização, sob a ótica da violação de direitos, não se restringiria a uma relação de gênero, mas, de forma mais ampla, diz respeito a uma relação de dominação do saber científico sobre o saber feminino. Situação identificada na experiência de gestantes que mesmo quando atendidas por uma profissional mulher, esta atuou e demonstrou ter incorporado os saberes da categoria:

A obstetrícia e ginecologia se dedicam ao controle do corpo feminino e ainda hoje é exercida, na sua maioria, por profissionais do sexo masculino mas também por mulheres que incorporam atitudes e sa- beres da categoria a qual pertencem, e a medicina é androcêntrica, ou seja seu saber e formas de intervenção pode ser vistos e entendidos como masculi$\operatorname{nos}^{29}($ p.743).

Essas observações nos remetem a estudos realizados por Martins ${ }^{2}$ em que analisa que a partir da construção e ampliação da atuação da medicina obstétrica, embasada em uma suposta autoridade científica que se impõe as demais formas de saber, instaura-se um cenário que propicia diferentes formas de violência sobre a mulher e seu corpo. A medicina obstétrica, então, passa a fornecer os subsídios teóricos que perpetuam diversas formas de diferenças: sexuais, sociais assim como as desigualdades de gênero ${ }^{2}$.

Fazendo uso dessa perspectiva os artigos afirmam que o modelo de parto medicalizado tem submetido às mulheres a relações de dominação que cerceiam sua autonomia e liberdade. Esse cerceamento associado à falta de informação e preparo sobre o parto, por parte das mulheres, tem dificultado uma experiência de parto com maior segurança e autodeterminação:

(...) Em uma relação assimétrica profissional de saúde/usuária e dependente dos médicos para se informarem, as mulheres têm dificuldade em participar das decisões relativas ao seu parto, sentindo-se menos capacitadas para escolher e fazer valer seus desejos frente às 'questões técnicas' levantadas pelos médicos ${ }^{30}$ (p.2487).

Da mesma forma como observado na análise das categorias anteriores, vemos um descolamento entre a utilização do termo medicalização e os argumentos e conceitos que guiam as análises. Embora a discussão de violência se paute no gênero, somente em 08 trabalhos desta categoria XXVI, XXXIII, XLV-XLVI, LXI, LXIV, LXVII, XCIV (Quadro 1) foram encontradas referências a obras que tratavam o conceito de medicalização, sob o viés de gênero.

\section{Medicalização e cenário do parto}

Nessa categoria encontramos o sentido de medicalização do parto associado ao cenário onde o parto é realizado. Os artigos $(\mathrm{n}=34) \mathrm{I}$, IV, VII, IX, XII-XIII, XVI-XVII, XXV, XXVIII, XXXI -XXXII, XXXVIII, XL, XLII-XLIV, L, LVI, LX, LXII, LXV-LXVI, LXVIII-LXIX, LXXII-LXXIII, LXXIX, LXXXI, LXXXIII, LXXXVI, XCI, XCV, CI (Quadro 1) destacam que o espaço físico do hospital propicia a excessiva medicalização da assistência ao trabalho de parto e parto, no que tange ao uso de intervenções assim como em relação à escolha da via de parto. 
Alguns desses artigos apontam que as circunstâncias inerentes a um ambiente hospitalar podem contribuir para o aumento das dores $\mathrm{e}$ provocar um stress na mulher durante o trabalho de parto, que resultam em situações que podem prejudicar a evolução de um parto normal, ou ainda que levem a indicações de intervenções, que se não estivesse naquele ambiente possivelmente não aconteceriam:

A internação da parturiente modifica sua rotina de afazeres básicos e simples como tomar banho e alimentar-se. $O$ ambiente hospitalar, com seus sons, cheiros, luzes e pessoas, causa estresse e tensão que concorrem para o aumento da dor do parto $^{2,10,11} .^{31}$ (p.307).

Diante desta situação, os artigos sinalizam para a existência de uma insatisfação tanto por parte das mulheres, quanto por parte de alguns profissionais por conta dos resultados negativos que este modelo estaria provocando. Nesse sentido recomendam a realização de mudanças no espaço físico onde os partos seriam realizados, em um processo que conduziria a uma chamada humanização da assistência. Tais recomendações incluem a realização de partos em domicílio, reconstrução de espaços hospitalares com a intenção de criação de um ambiente acolhedor que facilitasse e propiciasse a evolução do trabalho de parto; como também de criação de novos espaços, dentro ou fora do hospital, como forma de enfrentamento da medicalização da assistência. Alguns desses artigos fazem referência as negociações, as políticas e as ações que perpassaram pelo processo de tentativa de transformar tais recomendações em uma nova realidade:

(...), o Ministério da Saúde implanta os Centros de Parto Normal ou Casas de Parto (CP) no SUS por meio da Portaria/GM n.o 985, de 5 de agosto de 1999. Estes Centros objetivam promover a humanização e a qualidade do atendimento à mulher na assistência ao parto normal sem distócia ou de baixo risco. Eles podem funcionar fisicamente integrados ou isolados do hospital e as enfermeiras obstétricas compõem a equipe profissional mini$m a^{32}$ (p.873).

Assim, a construção e instalação das Casas de Parto e dos Centros de Parto Normal passam a ser apresentadas como elemento importante para configuração desse novo quadro, por vezes, nomeado como "desmedicalizante" e que por sua vez estaria relacionado a mudança de uma cultura hospitalar, rumo a humanização da assistência.

\section{Medicalização do parto como reflexo da medicalização da sociedade}

Os artigos agrupados nessa categoria $(\mathrm{n}=25)$ IX, XXII, XXVII, XXXIV, XXXVI, XXXIX, XLIV, XLVI, LI, LIV, LVII, LX-LXI, LXV-LXVII, LXXIII-LXXIV, LXXXII, LXXXV-LXXXVI, LXXXIX, XCII, XCVI, XCVIII (Quadro 1) identificam a medicalização do parto como um processo complexo, já que a medicalização não estaria restrita a área da saúde, se constituindo em um processo mais amplo relacionado a um modelo de sociedade, que se consolidou na época moderna. Neste processo, diferentes fatores atuariam de forma simultânea interferindo nas escolhas e procedimentos que dariam forma ao modelo de assistência:

A medicalização do parto é um reflexo da medicalização social, descrita como um processo sociocultural complexo que transforma em necessidades médicas as vivências, os sofrimentos e as dores que antes eram administradas no próprio ambiente familiar ou comunitário. A medicalização transforma culturalmente as populações, com um declínio na capacidade de enfrentamento autônomo das dores e adoecimentos ${ }^{2}$. Esta contribuiu para o declínio da capacidade da mulher em lidar com o fenômeno do parto, sua imprevisibilidade e as dores do trabalho de parto ${ }^{33}(\mathrm{p} .2396)$.

Nessa perspectiva, consideram que as análises sobre os cuidados e procedimentos que têm sido aplicados na condução do trabalho de parto, assim como aquelas que se concentram sobre as formas de nascer que têm se apresentado como predominantes, deveriam apreciar aspectos para além da área médica:

As práticas de parto e nascimento no Brasil sofreram profundas mudanças desde meados do século passado, com crescente hospitalização, medicalização e mercantilização. O panorama atual da parturição demonstra uma imbricada relação de elementos de naturezas distintas: politicos, econômicos, culturais, institucionais, profissionais, entre outros $^{34}(\mathrm{p} .886)$.

Nesses estudos, a medicalização não aparece como produto da atuação de um profissional específico, nem relacionada a um ambiente, nem como constitutiva de modelos polarizados; mas sim como processo em que diferentes atores envolvidos na assistência ao parto seriam copartícipes, cada qual em defesa de um interesse construído em meio a um processo de medicalização da vida:

Dessa forma, diferentes estudos vêm sugerindo que: fatores pessoais, da mulher e de seu ambiente 
social, ${ }^{3,5}$, bem como regionais e institucionais relacionados à organização dos serviços ${ }^{13}$ constituem aspectos não-médicos relacionados ao parto no Brasil, influenciando a cultura da prática obstétrica vigente ${ }^{35}$ (p.1052).

Segundo esses artigos, o poder de negociação de cada um desses atores sofreria variação de acordo com: 1) a função que desempenham; 2) o espaço em que se desenvolve a assistência; e 3) o conhecimento e o conjunto de informações que cada um deles dispõem. Estes fatores atuando de forma simultânea seriam relevantes para a tomada de decisão e desfecho dos procedimentos relativos ao parto:

Durante a gravidez e o parto, as mulheres vivenciam várias alterações físicas e emocionais e expressam, neste processo, valores e crenças, assim como se defrontam com a estrutura social e cultural dos profissionais dos serviços de saúde. (...) Os profissionais, durante o exercício da prática assistencial, também expressam sua maneira de compreender a doença, influenciada por aspectos culturais, sociais e pelo modelo de formação hegemônico. $O$ encontro entre esses dois sujeitos é sempre singular e influenciado pela dimensão cultural e social; e, embora seja um espaço propício ao diálogo, é permeado por uma relação assimétrica de poder $e$ de saber com grande potencial de influência na escolha do tipo de parto, do itinerário terapêutico e da qualidade da assistência prestada às gestantes $^{8-10} .^{36}$ (p.192).

O tipo de abordagem e perspectiva apresentada nessa categoria nos remete aos autores que tratam a medicalização como um fenômeno de ordem sociocultural que também se encontra internalizado nos indivíduos, como encontrados nos trabalhos de Foucault ${ }^{14}$; que se manifesta em sua forma de viver, onde se incluem as suas escolhas a partir dos saberes que circulam em toda sociedade, e que marca a forma como pensamos e vivemos, que se relaciona as abordagens desenvolvidas por Clarke et al. ${ }^{19}$.

\section{Considerações finais}

A análise sobre os sentidos atribuídos ao conceito de medicalização do parto pela literatura de assistência ao parto no Brasil foi desenvolvida tomando como base cinco categorias em que o conceito de medicalização assumiu diferentes sentidos. Em quatro delas: medicalização e intervenções; medicalização e disputa profissional; medicalização e violação de direitos das gestantes e medicalização e cenário do parto encontramos um predomínio de sentidos que exploraram uma interface entre medicalização e humanização, que são apresentadas em uma posição relacional de oposição, constituindo-se como duas supercategorias analíticas que perpassam as discussões sobre assistência ao parto.

Embora esses artigos apresentem uma proposta de estudo que trazem como pano de fundo a análise dos dois conceitos: "medicalização" e "humanização", no seu desenvolvimento, acabaram por centralizar suas considerações sobre o conceito de humanização, demonstrando que, por vezes, a discussão de humanização já pressupõe uma contraposição à medicalização, mesmo que a discussão teórica sobre este último conceito esteja ausente.

De forma geral percebemos que além da pouca discussão teórica sobre o conceito de medicalização, os sentidos encontrados nos artigos que compõem essas quatro categorias, estiveram focados nas primeiras produções teóricas sobre o conceito, o que, a nosso ver, limitou a possibilidade de aprofundar uma discussão que trouxesse como pauta as complexas conexões existentes entre o modelo de assistência ao parto e aspectos mais abrangentes histórico-socialmente construídos.

Observa-se que a discussão da relação entre medicalização e humanização tem um predomínio de uma crítica à medicalização em que o formato adotado conduz o leitor a inferir uma oposição entre os dois conceitos, em que a existência de um excluiria o outro. A utilização do conceito de medicalização se impôs como contraponto a uma prática que se vê como positiva. Assim a medicalização se transforma no inverso da humanização, ao invés de se caracterizar como um contexto que a subjaz.

Fugindo a este modelo de análise, a categoria "medicalização do parto como reflexo da medicalização da sociedade" se concentra em torno de um sentido de medicalização do parto como parte de um processo mais amplo que envolve diferentes atores que seriam copartícipes no processo de assistência. A medicalização do parto ali entendida se relacionaria ao processo de medicalização da vida, em que se percebe uma maior proximidade com aspectos complexos de construção sociocultural que se relacionam com as práticas assistenciais do modelo hegemônico vigente, e que requer considerações para além de uma suposta contraposição medicalização versus humanização.

Por fim percebemos que as publicações analisadas projetaram propostas de mudanças que 
indicam uma inquietação quanto à eficácia do modelo de assistência ao parto. Entendemos que a discussão em torno do conceito de medicalização do parto continua sendo pertinente, e reafirmamos que ela deve estar articulada aos aspectos mais gerais que compõe a sociedade moderna, no sentido de possibilitar a criação de uma assistência ao parto onde a mulher e suas necessidades sejam o centro, e não o uso (ou não) de intervenções.

\section{Colaboradores}

Todos os autores participaram de todas as etapas da elaboração do artigo.

\section{Agradecimentos}

O presente trabalho foi realizado com o apoio da Coordenação de Aperfeiçoamento de Pessoal de Nível Superior Brasil - (CAPES) - Código de Financiamento 001. 


\section{Referências}

1. Mott ML. Assistência ao parto: do domicílio ao hospital (1830-1960). Proj História 2002; (25):197-219.

2. Martins APV. Visões do feminino: a medicina da mulher nos séculos XIX e XX. Rio de Janeiro: Editora Fiocruz; 2004.

3. Nagahama EEI, Santiago SM. A institucionalização médica do parto no Brasil. Cien Saude Colet 2005; 10(3):651-657.

4. Diniz SG. Humanização da assistência ao parto no Brasil: os muitos sentidos de um movimento. Cien Saude Colet 2005; 10(3):627-637.

5. Boaretto MC. Avaliação da Política de Humanização ao Parto e Nascimento no Município do Rio de Janeiro [dissertação]. Rio de Janeiro: Escola Nacional de Saúde Pública/Fundação Oswaldo Cruz; 2003.

6. World Health Organization (WHO). Appropriate technology for birth. Lancet 1985; 24(2):436-437.

7. Matos GC, Escobal AP, Soares MC, Härter J, Gonzales RIC. A trajetória histórica das políticas de atenção ao parto no Brasil: uma revisão integrativa. Rev Enferm UFPE 2013; 7(n. esp.):870-878.

8. Nakano AR. Uso de tecnologias e as transformações nas práticas sociais e de nascimento no Brasil: uma normalização da cesárea? [tese] Rio de Janeiro: Instituto Fernandes Figueira; 2015.

9. Diniz SG. Parto no Brasil [entrevista a Mariana Portella e Allan Monteiro]. Rev Colet 2015; 15:1-6.

10. Zorzanelle RT, Ortega F, Bezerra Jr B. Um panorama sobre as variações em torno do conceito de medicalização entre 1950-2010. Cien Saude Colet 2014; 19(6):1859-1868.

11. Davis JE. How medicalization lost its way. Society 2006; 43(6):51-56.

12. Zola I. Medicine as an institution of social control. Sociol Rev 1972; 4:487-504.

13. Foucault M. Microfísica do Poder. Rio de Janeiro: Edições Graal; 1979.

14. Foucault M. História da sexualidade I: a vontade de saber. Rio de Janeiro: Edições Graal; 2006.

15. Illich I. A expropriação da saúde: nêmesis da Medicina. Rio de Janeiro: Nova Fronteira; 1975.

16. Gaudenzi P, Ortega F. O estatuto da medicalização e as interpretações de Ivan Illich e Michel Foucault como ferramentas conceituais para o estudo da desmedicalização. Interface (Botucatu) 2012; 16 (40):21-34.

17. Lupton D. Foucault and the medicalisation critique. In: Foucault M. Health and Medicine. London: Routledge; 1997. p. 94-110.

18. Conrad P. Medicalization and social control. Annu Rev Sociol 1992; 18:209-232.

19. Clarke AE, Mamo L, Fosket JR, Jishman JR, Shim JK. Biomedicalization: Technoscience, Health and Illness in the US. Durham: Duke University Press; 2010.

20. Vasconcelos AA. A atuação das enfermeiras na humanização do parto e nascimento no Distrito Federal [dissertação]. Brasília: Universidade de Brasília; 2010.

21. Narchi NZ, Cruz EF, Gonçalves R. O papel das obstetrizes e enfermeiras obstetras na promoção da maternidade segura no Brasil. Cien Saude Colet 2013; 18(4):1059-1068.

22. Chaves IMM, Pereira RIC, Bastos CO, Pereira RR. O Anestesiologista no Parto Humanizado. CLASA 2002; lis- 16948 .
23. Seibert SL, Barbosa JLS, Santos MS, Vargens OMC. Medicalização x Humanização: o cuidado ao parto na história. Rev Enferm UERJ 2005; 13:245-251.

24. Vargas PB, Vieira BDG, Alves VH, Rodrigues DP, Leão DCMR, Silva LA. A assistência humanizada no trabalho de parto: percepção das adolescentes. Rev Pesqui Cuid Fundam 2013; 6(3):1021-1035.

25. Moura CFS, Lopes GT, Santos TCF. Humanização e desmedicalização da assistência à mulher: do ensino à prática. Rev Enferm UERJ 2009; 17(2):182-187.

26. Vargens OMC, Progianti JM, Silveira ACF. O significado da desmedicalização da assistência ao parto no hospital: análise da concepção de enfermeiras obstétricas. Rev Esc Enferm USP 2008; 42(2):339-346.

27. Narchi NZ. Atenção ao parto por enfermeiros na Zona Leste do município de São Paulo. Rev Bras Enferm 2009; 62(4):546-551.

28. Diniz SG, Salgado HO, Andrezzo HFA, Carvalho PGC, Carvalho PCA, Aguiar CA, Niy Y. Violência obstétrica como questão para a saúde pública no Brasil: origens, definições, tipologia, impactos sobre a saúde materna, e propostas para a sua prevenção. J Hum Growth Dev 2015; 25(3):377-376.

29. Teixeira NZF, Pereira WR. Parto hospitalar - experiências de mulheres de periferia de Cuiabá - MT. Rev Bras Enferm 2006; 59(6):740-744.

30. Gama AS, Giffin KM, Angulo-Tuesta A, Barbosa GP, D’Orsi E. Representações e experiências das mulheres sobre a assistência ao parto vaginal e cesárea em maternidades pública e privada. Cad Saude Publica 2009; 25(11):2480-2488.

31. Macedo PO, Progianti JM, Vargens OM, Santos VLC, Silva CA. Percepção da dor pela mulher no pré-parto: a influência do ambiente. Rev Enferm UERJ 2005; 13:306-312.

32. Pereira ALF, Moura MAV. Hegemonia e contra-hegemonia no processo de implantação da Casa de Parto no Rio de Janeiro. Rev Esc Enferm USP 2009; 43(4):872-879.

33. Leão MRC, Riesco MLG, Schneck CA, Angelo M. Reflexões sobre o excesso de cesarianas no Brasil, e a autonomia das mulheres. Cien Saude Colet 2013; 18(8):2395-2400.

34. Nakano AR, Bonan C, Teixeira LA. A normalização da cesárea como modo de nascer: cultura material do parto em maternidades privadas no Sudeste do Brasil. Physis 2015; 25(3):885-904.

35. Freitas PF, Sakae TM, Jacomino MEMLP. Fatores médicos e não-médicos associados às taxas de cesariana em um hospital universitário no Sul do Brasil. Cad Saude Publica 2008; 24(5):1051-1061.

36. Pires D, Fertonani HP, Conill EM, Matos TA, Cordova FP, Mazur CS. A influência da assistência profissional em saúde na escolha do tipo de parto: um olhar sócio antropológico na saúde suplementar brasileira. Rev. Bras. Saude Matern Infant 2010; 10(2):191-197.

Artigo apresentado em 05/10/2018

Aprovado em 28/01/2019

Versão final apresentada em 30/01/2019 